\title{
Size of the prize: the value of closing pasture yield gaps on heterogeneous soil types in a dairy farm in Canterbury, New Zealand
}

\author{
Anna L. TAYLOR ${ }^{1 *}$, Mariana P. ANDREUCCI ${ }^{2}$, Sue M. ZYDENBOS ${ }^{1}$, Ahmed ELNAGGAR $^{3}$, \\ Michael J. MANNING ${ }^{4}$, Ants H.C. ROBERTS ${ }^{5}$, Alister METHERELL and Robyn A. DYNES ${ }^{1}$ \\ ${ }^{1}$ AgResearch, Lincoln Research Centre, Private Bag 4749, Christchurch \\ ${ }^{2}$ Field Research Centre, Agriculture and Life Sciences Faculty, Lincoln University, \\ PO Box 85084, Lincoln 7674, New Zealand \\ ${ }^{3} \mathrm{AgResearch,} \mathrm{Invermay} \mathrm{Research} \mathrm{Centre,} \mathrm{Private} \mathrm{Bag} \mathrm{50034,} \mathrm{Mosgiel}$ \\ ${ }^{4}$ Ravensdown Limited, Hornby, Christchurch, New Zealand \\ ${ }^{5}$ Ravensdown Limited, P.O. Box Pukekohe 2340, New Zealand \\ *Corresponding author: anna.taylor@agresearch.co.nz
}

\begin{abstract}
Identifying opportunities to improve pasture production on irrigated Canterbury dairy farms is complex. This paper focuses on managing soil zones to optimise pasture production. Using electromagnetic induction (EM38) mapping, the area under a single centre pivot irrigator was characterised into soil zones of 'low', 'medium' and 'high', according to moisture and texture. Actual measurements of irrigation and soil characteristics were used in the model APSIM to estimate pasture production in 'low' and 'medium' soils under constant irrigation, giving an annual difference of $2900 \mathrm{~kg} \mathrm{DM} / \mathrm{ha}$ between the zones. In a typical irrigated Canterbury System 4 dairy farm modelled in FARMAX, with $20 \%$ 'low' and $80 \%$ 'medium' soil zones, increasing pasture in the 'low' zone to that of the 'medium' zone gave an increase of $580 \mathrm{~kg} \mathrm{DM} / \mathrm{ha}$. This produced $51 \mathrm{~kg} /$ ha more milksolids and increased stocking rate by $0.2 \mathrm{cow} / \mathrm{ha}$, giving a profit increase of $\$ 298 /$ ha/year. This improvement on a 255 ha farm was estimated at $\$ 75,000$ per annum. On a regional scale, increasing productivity of 52,900 ha of 'low' zone soils on irrigated farms in Canterbury would contribute $\$ 14 \mathrm{M}$ to the economy. Taking a spatial management approach to understand variability in pasture can identify opportunities and potential value.
\end{abstract}

Keywords: innovation, APSIM, FARMAX, electromagnetic induction

\section{Introduction}

Dairy production in the Canterbury region of New Zealand is predominately based on intensified systems that, from now on, need to shift towards a sustainable intensification approach to be able to thrive. Previous forms of intensification, such as the increase of nitrogen fertilisation or irrigation, need to be re-addressed in a smarter and more efficient way to secure the longevity of dairy production. The Canterbury region has seen a $42 \%$ increase in the number of dairy herds from $2008 / 2009$ to $2018 / 2019$ seasons (LIC/DairyNZ 2009, 2019).

The Canterbury region is known for its heterogeneity of soil types (Di and Kemp 1989), which results in a diversity of pasture production potentials (Clark et al., 2010), within and among paddocks within a single farm. This pasture production variability is an opportunity to explore possibilities and strategies to address and close the yield gap (Van Ittersum et al., 2013). The characterisation of such gaps helps to identify the potential for efficiency gains within existing resources, although any improvements to close the production gap between areas of low and high yield potential needs to be environmentally and economically sustainable.

Soil and yield maps are tools used to identify challenges and opportunities for improvement in pastoral systems. An innovation systems approach (Zydenbos et al., 2019) was used to identify factors contributing to variation in pasture production on a case study farm, such as: soil characteristics, irrigation management and grass grub populations. This approach combines technical research with the wider network of expertise and recognises the process of creating, sharing and putting knowledge into productive use (Hall 2007). Farm systems modelling can explore scenarios where potential strategies of sustainable intensification are considered, based on information generated by those tools. These scenarios can then be evaluated to establish the 'size of the prize' from attempting to close existing yield gaps.

The following study used a series of modelling scenarios to estimate potential pasture production based on plant available water of different soil zones on an intensive dairy farm in Canterbury, New Zealand. This innovation systems approach was helped in interpretation by using data and knowledge from many sources to understand the variation in the farm system to enable modelling of the potential value of mitigating this variation. 


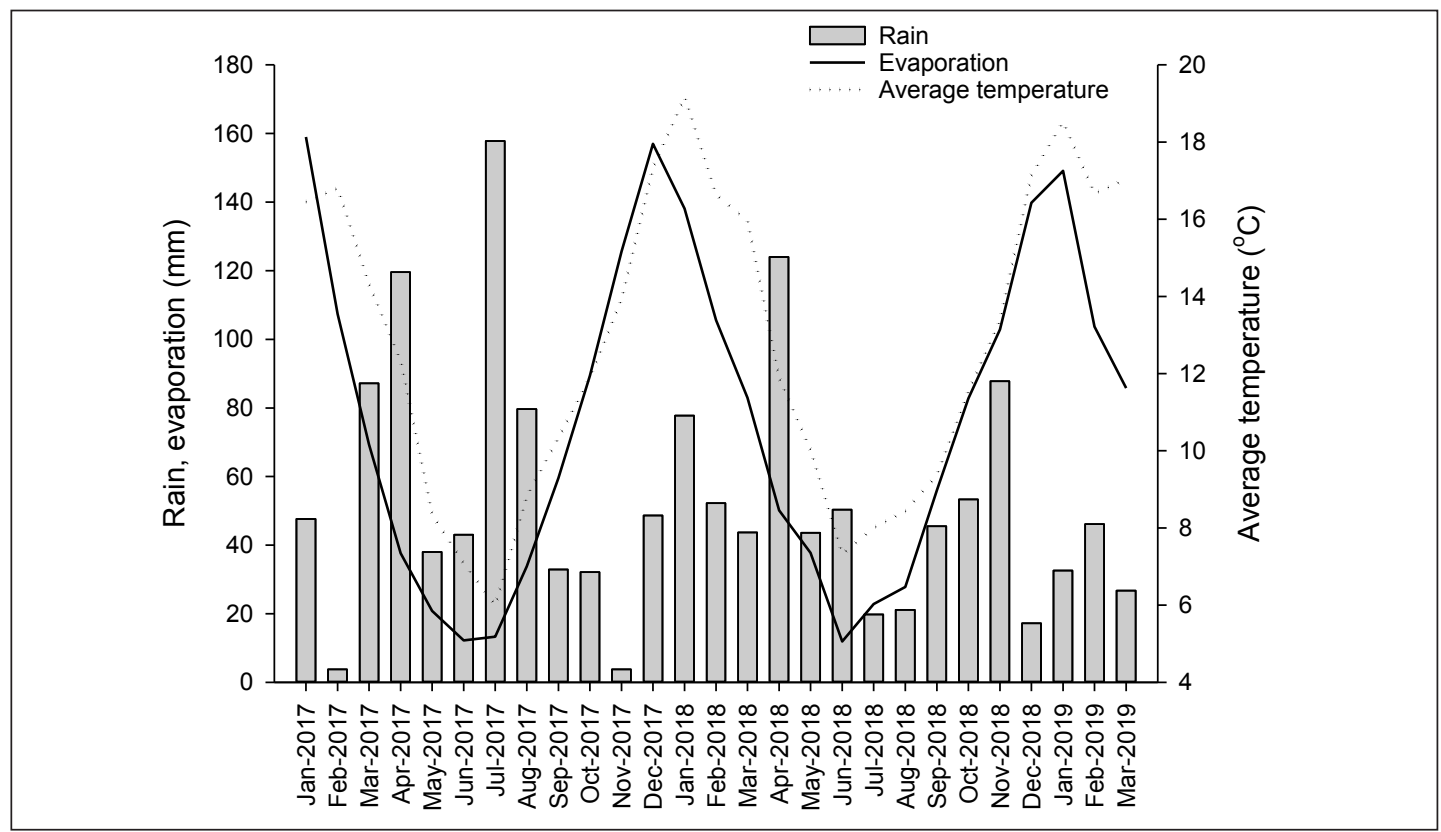

Figure 1 Monthly rain, evaporation and average temperature for the period from January of 2017 to March of 2019 for Rakaia Island, Canterbury, New Zealand.

\section{Materials and Methods}

An innovation systems approach (Hall 2007; Zydenbos et al., 2019) was used to integrate data from different sources. These sources included weather data, dry matter production measurements, irrigation and fertiliser application, electromagnetic induction (EM38) maps of soil properties, farmer and agribusiness knowledge and soil and farm system modelling. This co-innovation process enabled an understanding of the variation on the farm (soil, pasture growth, irrigation) and to model the benefit if it was possible to overcome this variation.

\section{Rakaia Island Dairies}

Rakaia Island Dairies (RID) operates four independent dairy units $45 \mathrm{~km}$ south-west of Lincoln, Canterbury, New Zealand. All pastures were perennial ryegrass (Lolium perenne) and white clover (Trifolium repens), grazed by dairy cows at the 2-3-leaf stage. The current study focused on the Dairy 1 unit under a $564 \mathrm{~m}$ long variable rate irrigation (VRI) centre pivot irrigator that covers approximately 100 ha. At the time of the study, VRI was utilised to avoid water application to farm tracks and the irrigator wheel tracks. Monitoring at RID included soil moisture, pasture production and variation, irrigation amount and intensity.

\section{Weather data}

Rain, temperature (Figure 1) and radiation were obtained from the virtual climate station network (Tait and Turner 2005) in the NIWA database (NIWA 2020).
Total annual rainfall for 2017 was $694.1 \mathrm{~mm}$ and 636.3 $\mathrm{mm}$ for 2018, while total rainfall for the months of January, February and March of 2019 was $105.4 \mathrm{~mm}$. Monthly evaporation was higher than the monthly rainfall for 6 months in 2017, 9 months in 2018 and for the same 3 month period in 2019. This resulted in an annual total moisture deficit of $190.9 \mathrm{~mm}$ of 2017 , $222.2 \mathrm{~mm}$ for 2018 and $233.2 \mathrm{~mm}$ for the three-month period of 2019 .

\section{Soil types and soil moisture evaluation}

The study area under the central pivot was located on soils from the Rakaia, Waimakariri, Selwyn and Rangitata families, based on data from S-map (Manaaki Whenua Landcare Research 2019). These weathered fluvial recent soils (RFW) of loam, sandy and silty loam textures can be moderately deep or shallow and stony. Maps were available for the area under the VRI pivot, collected in autumn using a towbehind dual electromagnetic (EM38) machine (https:// precisionagriculture.org.nz/) that provided maps of apparent electrical conductivity $\left(E C_{a}\right)$ at a depth of $0-50 \mathrm{~cm}$ and $1 \mathrm{~m}$, and a resolution of $12 \mathrm{~m}$. The $E C_{a}$ maps were subsequently used to generate maps of soil texture and water holding capacity (Hedley et al., 2013). Soils were grouped into three zones based on an equi-distribution of the $E C_{a}$ range measured by EM and are referred to as 'low' $(2-3.5 \mathrm{mS} / \mathrm{m})$, 'medium' $(3.75-5.25 \mathrm{mS} / \mathrm{m})$ and 'high' $(6-7.5 \mathrm{mS} / \mathrm{m})$ water holding capacity. These zones covered 17 ha, 69 ha and 


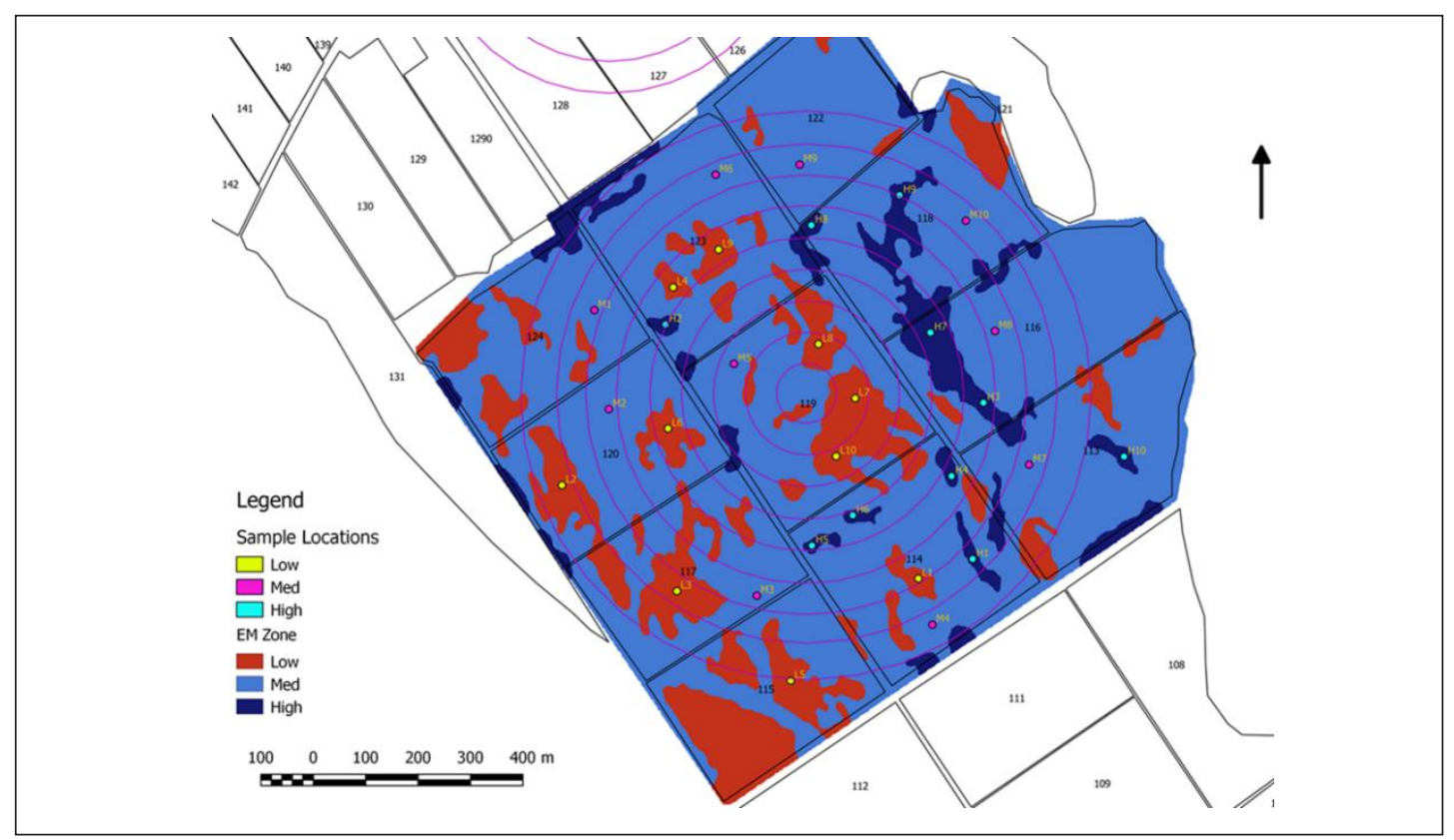

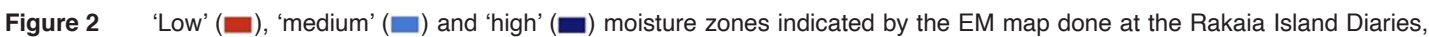

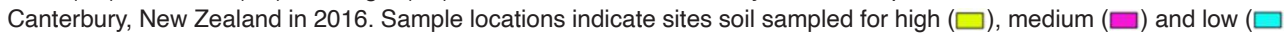
) EM zones. Plot produced by ArcGIS Pro:2.8.0

22 ha respectively (Figure 2). This study focused on the 'low' and 'medium' zones. A characteristic of the 'low' zone was lower plant available water capacity (PAWC) with approximately $53 \%$ stones from 0 to $20 \mathrm{~cm}$ depth, $65 \%$ stones from 20 to $34 \mathrm{~cm}$ depth and $67 \%$ stones from 34 to $99 \mathrm{~cm}$ depth. The 'medium' zone had higher PAWC and less stones than the 'low' zone. Stones were seen in soil trenches on the 'medium' zone but were not considered substantial enough to be quantified in the lab.

Following EM maps, observed data were obtained from Time Domain Reflectometry probes (TDR; ML3 ThetaProbe, Delta-T Devices) and electromagnetic Time Domain Transmission tapes (TDT; Aquaflex, Streat Instruments Ltd., New Zealand) installed to monitor soil moisture from 28 March 2017 until 5 March 2019. Horizontal TDR probes provided readings at $140 \mathrm{~mm}, 320 \mathrm{~mm}$ and $500 \mathrm{~mm}$ depth for the 'low' zone and at $170 \mathrm{~mm}, 300 \mathrm{~mm}$ and $430 \mathrm{~mm}$ depth for the 'medium' zone. Readings were logged at $30 \mathrm{~min}$ intervals. On 18 October 2018, the TDR probes in the 'medium' zone of soil moisture had to be re-installed due to mechanical damage.

There were two TDT tapes for each moisture zone. These were $3 \mathrm{~m}$ long and logged hourly readings. The first tape (top depth) was installed on an angle and measured soil moisture from a starting depth of 100 $\mathrm{mm}$ down to $300 \mathrm{~mm}$. The second tape was installed horizontally at $500 \mathrm{~mm}$ depth.

\section{Dry matter production}

Weekly whole farm walks estimated pasture height using either a C-Dax pasture meter or a rising plate meter. These data were used to determine pasture growth rates and pasture mass. Pasture height measurements were converted to pasture mass using the recommended equations for Canterbury, i.e., $\mathrm{kg} \mathrm{DM} / \mathrm{ha}=(\mathrm{mm} \times 18.1)$ +729 (C-Dax Ltd 2019) for the pasture meter data and (140 x 'clicks') +355 (King et al., 2010) for the rising plate meter data.

\section{Irrigation and fertiliser}

Urea was applied from January to April and then from September to December at a rate of $260 \mathrm{~kg} \mathrm{~N} /$ ha/year. The uniformity of five centre pivot irrigators on RID farm was measured during April 2016, and the VRI pivot again in June 2017, using the 'bucket test' protocol or 'catch can' method (Thomas et al., 2006). This involved placing a bucket at every $5 \mathrm{~m}$ along the length of the pivot $(590 \mathrm{~m})$ and measuring the amount of water collected during one pass. The irrigation application under the VRI pivot on Dairy Unit 1 ranged from $1-12 \mathrm{~mm}$ in 2016 with an average of $4( \pm 1.35)$ $\mathrm{mm}$ and $2-14 \mathrm{~mm}$ in 2017 with an average of $9( \pm 2.13)$ $\mathrm{mm})$.

Irrigation amount and intensity was monitored using tipping buckets (Rain Collector II, Davis Instruments, USA, $0.2 \mathrm{~mm}$ per tip). Two sets of 10 tipping buckets each were installed in 'low' and 'medium' zones. Data 

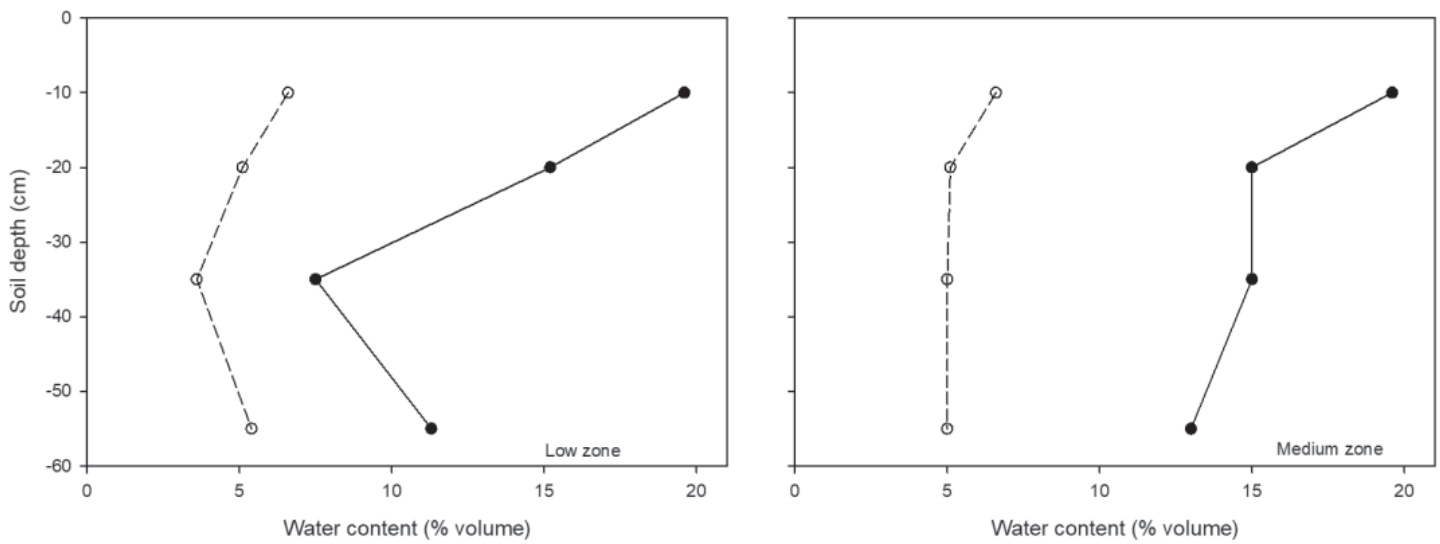

Figure 3 Drained upper limit (•) and lower limit ( $\circ)$ for 'low' and 'medium' soil moisture zones estimated from visual assessments of observed soil moisture variation from 2017 to 2019, at Rakaia Island, Canterbury, New Zealand.

for every tipping bucket were summarized within 5 min intervals. Three buckets with highest positive correlation in readings between them were selected and the data averaged to mitigate possible issues with soil and grass particles blocking water input. Information provided by the GPS location of the pivot was used to separate 'irrigation' from 'rain' events. Monthly irrigation for the low and medium zones is presented in Table 1. This schedule was used to model soil moisture at the 'low' and 'medium' zones of soil moisture.

\section{APSIM soil water modelling}

Observed soil water content collected from the site was

Table 1 Monthly irrigation applied for 'low' and 'medium' zones of soil moisture from 2017 to 2019 at Rakaia Island, Canterbury New Zealand, from tipping bucket data.

\begin{tabular}{lcc}
\hline Month/Year & ‘Low' zone & 'Medium’ zone \\
\hline Dec/2017 & 96.0 & 65.7 \\
Jan/2018 & 94.1 & 60.0 \\
Feb/2018 & 66.0 & 37.8 \\
Mar/2018 & 15.3 & 5.7 \\
Apr/2018 & 20.3 & 21.5 \\
May/2018 & 3.6 & 0 \\
Jun/2018 & 0 & 0 \\
Jul/2018 & 0 & 0 \\
Aug/2018 & 3.4 & 0 \\
Sep/2018 & 24.8 & 14.1 \\
Oct/2018 & 64.5 & 39.2 \\
Nov/2018 & 36.8 & 31.3 \\
Dec/2018 & 45.4 & 24.9 \\
Jan/2019 & 103.4 & 76.2 \\
Feb/2019 & 68.3 & 69.0 \\
\hline
\end{tabular}

simulated in APSIM by the SoilWater module (APSIM 2020) from December 2017 until March 2019. This module is a cascading water balance approach where soil characteristics, such as lower limit (LL15), drained upper limit (DUL) and saturated volumetric water content (SAT), were used to indicate profile water holding capacity (PAWC). Initially, soil parameters for the 'low' and 'medium' zone soils were based on previous laboratory observations of bulk density (BD), drained lower and upper limits and saturation for this area. Results were then corrected for the stone content. This was needed, because APSIM considers only fine earth in its BD. Parameters like DUL, LL and SAT were then further adjusted based on visual observations of the water extraction patterns obtained from the observed soil moisture data (Figure 3). The root exploration front (XF) was set up to allow water extraction down to 55 cm depth.

The quality of estimates of soil moisture were evaluated based on residual mean square deviation (RMSD) and visual assessment of fit between predicted and observed data. Finally, estimated soil moisture content was used to estimate annual dry matter production of pasture for the 'low' and 'medium' zones, as described in the section below.

\section{APSIM pasture production modelling}

Pasture production was estimated by AgPasture, which is the model in the APSIM framework (Li et al., 2011). A pasture mix was modelled with initial dry matter (DM) mass of 1500 and $500 \mathrm{~kg} \mathrm{DM} / \mathrm{ha}$ for a generic ryegrass and white clover pasture, respectively. Rotational grazing was simulated every 21 days, until a residual mass of $1500 \mathrm{~kg} \mathrm{DM} / \mathrm{ha}$ was achieved and $70 \%$ of the defoliated $\mathrm{N}$ was returned to the soil as urine and dung. Daily irrigation was set through an 'operations' module where dates and amounts of water applied were inputted based on observed data (Table 1). 
AgPasture produces robust estimations of pasture production based on long term annual pasture production cycles (Li et al., 2011). For this reason, an average estimation of dry matter production based on 2 years was reported from July 2017 to June 2018 and from July 2018 to June 2019. Seasons start in July to allow the simulation of pasture production to begin from a full soil moisture water profile, which is typically observed throughout the winter period. Estimated mean monthly pasture growth rates were then compared with on-farm data of mean monthly growth rates obtained from weekly C-DAX and raising plate meter measurements.

\section{System modelling}

The modelling of a representative hypothetical Canterbury irrigated dairy farm was initially done by simulating the potential yield difference of the 'low' and 'medium' soil zones in APSIM. This modelling of the hypothetical production systems used a uniform irrigation schedule (Table 2), to allow for the direct comparison of the two scenarios. The irrigation season was simulated from September until April for the modelled period of July 2017 until June 2019. The start and end of the irrigation period (shoulder season) was characterised by one application of $5 \mathrm{~mm}$ on 21 September, 1 October and 4 April. From 16 October until 30 March an application of $10 \mathrm{~mm}$ was simulated every 5 days. This schedule provided a total application of $355 \mathrm{~mm}$ throughout each irrigation season.

The difference in average pasture production simulated by APSIM for the 'low' and 'medium' soil zones was further used to simulate a whole farm system with $20 \%$ 'low' and $80 \%$ 'medium' soil zones. As outlined in Zydenbos et al. (2019), a 'typical irrigated Canterbury System 4 dairy farm' was modelled in FARMAX Dairy Pro ${ }^{\circledR}$ version 8.0.1.33 (Bryant et al., 2010) to explore the impact of the simulated difference in the 'low' and 'medium' zones. This idealised farm

Table 2 Characterisation of the irrigation season for the modelling of hypothetical production systems based on 'low' and 'medium' soil moisture zones in Canterbury.

\begin{tabular}{lcccc}
\hline \multicolumn{2}{c}{ Shoulder season } & & \multicolumn{2}{c}{ Mid-season } \\
\cline { 5 - 5 } Date & Amount (mm) & & Month & Amount (mm) \\
\hline 21-Sep & 5 & & October & 40 \\
1-Oct & 5 & & November & 60 \\
4-Apr & 5 & & December & 60 \\
& & January & 60 \\
& & February & 60 \\
& & March & 60 \\
\hline
\end{tabular}

with $20 \%$ 'low' zone was 255 ha with a stocking rate of 2.9 cows/ha and milk production of $1124 \mathrm{~kg}$ milksolids/ ha (Table 3).

After simulating production at a farm scale, an extrapolation at regional scale was performed. The area of irrigated dairy pasture in Canterbury was estimated based on the Ministry for the Environment GIS vector layer irrigated land area for 2017 (Ministry for the Environment 2017a). This was overlayed on the Ministry for the Environment GIS $100 \mathrm{~m}$ by 100 $\mathrm{m}$ pixel raster layer for nitrate-nitrogen leaching from dairy livestock for 2017 (Ministry for the Environment 2017 b). Where more than $20 \%$ of an irrigated polygon intersected with the dairy leaching raster, it was deemed to represent irrigated Canterbury dairy land. This resulted in a total irrigated dairy area for Canterbury of 293,614 ha. This area was overlayed on S-map (August 2020 release) (Manaaki Whenua Landcare Research 2019) and a proportional area of each S-map sibling for the irrigated Canterbury dairy land was obtained. The total area of light (PAW $<40 \mathrm{~mm}$ ) and medium (PAW $\geq 40 \mathrm{~mm}$ and $<100 \mathrm{~mm}$ ) soils was calculated as 52,900 ha (18\%) and 117,209 ha (40\%) respectively, using the sibling attribute for potential available water down to $60 \mathrm{~cm}$ depth.

These values were combined with the FARMAX model results to estimate the potential value of yield loss between the 'low' and 'medium' zones on irrigated Canterbury dairy farms.

\section{Results}

\section{Soil water modelling}

Soil water modelling for the 'low' zone is presented in Figure 4. The RMSD of the TDR probe estimations of

Table 3 Parameters used for system modelling and the results of increasing annual dry matter production by $580 \mathrm{~kg} \mathrm{DM} / \mathrm{year}$ (100\% 'medium' zone)

\begin{tabular}{lcc}
\hline Parameter' $^{\prime}$ & \multicolumn{2}{c}{ Scenario } \\
\cline { 2 - 3 } & $\begin{array}{c}\text { 20\% 'low' } \\
\text { zone and } \\
\begin{array}{c}\text { 80\% 'medium' } \\
\text { zone }\end{array}\end{array}$ & $\begin{array}{c}100 \% \\
\text { 'medium' } \\
\text { zone }\end{array}$ \\
\hline Effective area (ha) & 255 & 255 \\
Stocking rate (cows/ha) & 2.9 & 3.1 \\
Potential pasture growth (t DM/ha) & 12.8 & 13.4 \\
Cow numbers (1 July) & 783 & 814 \\
Peak cows milked & 749 & 780 \\
Milksolids (kg/ha) & 1124 & 1175 \\
Profit (\$/ha/year) & 2166 & 2464 \\
\hline
\end{tabular}

${ }^{1}$ obtained from (DairyNZ 2015/16); ${ }^{2}$ based on a milk price of $\$ 7.10 / \mathrm{kg}$ MS (Fonterra 2019-2020) and FARMAX prices from 2019/20 auto schedule. 

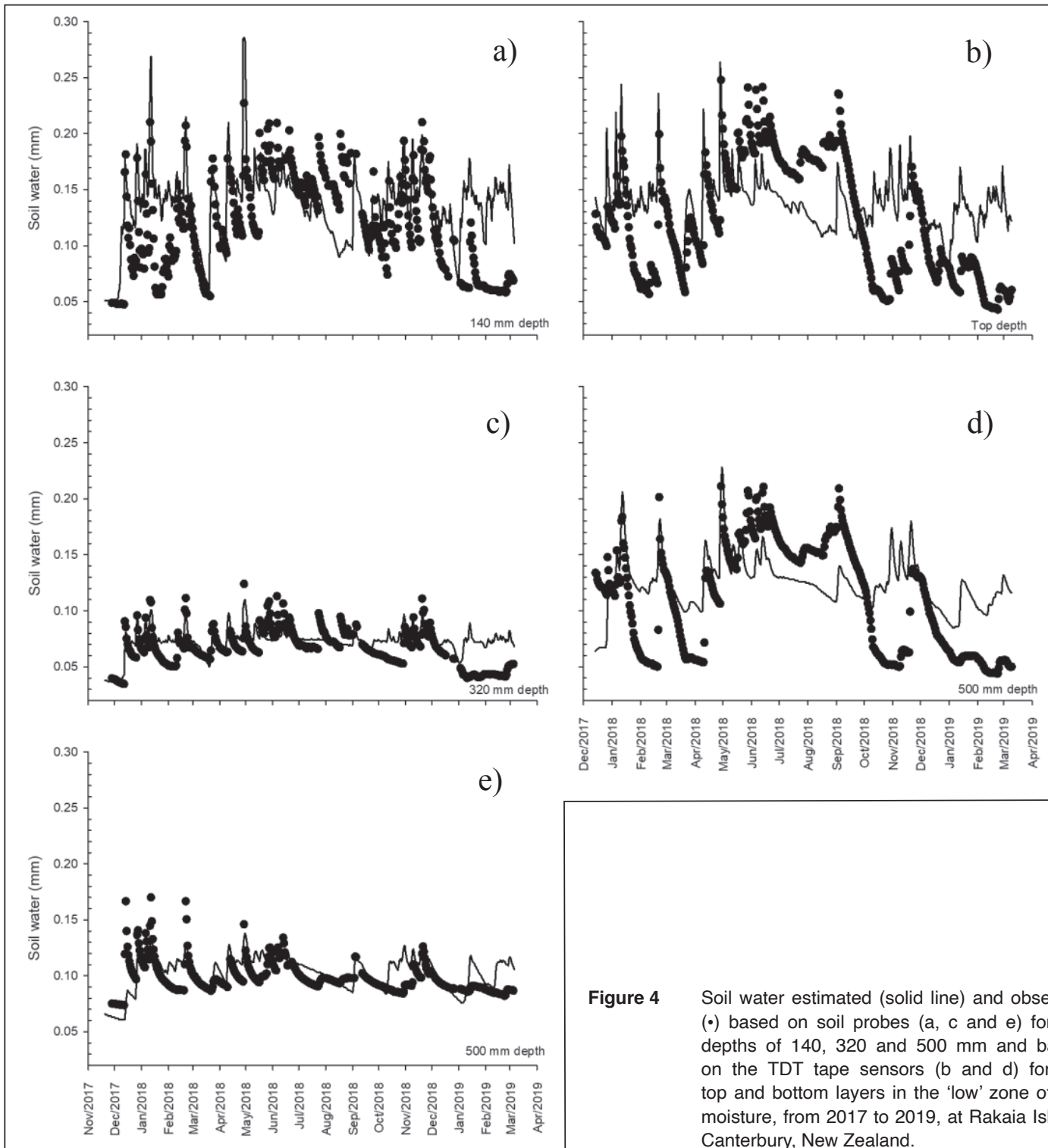

Figure 4 Soil water estimated (solid line) and observed $(\bullet)$ based on soil probes (a, c and e) for the depths of 140,320 and $500 \mathrm{~mm}$ and based on the TDT tape sensors ( $b$ and $d$ ) for the top and bottom layers in the 'low' zone of soil moisture, from 2017 to 2019, at Rakaia Island, Canterbury, New Zealand.

volumetric water content for the layer of $140 \mathrm{~mm}$ depth was $5 \%$, whereas the estimations for the depths of 320 and $500 \mathrm{~mm}$ had values of $2 \%$. The TDT tape-based estimations had RMSD values of 5\% for the top layer and $4 \%$ for the bottom layer. Based on these values and a more reasonable visual fit between estimated and observed values from the TDR probes (Figure 4), estimations of soil moisture based on these probes were chosen to produce estimates of annual dry matter production for the 'low' zone of soil moisture. Based on the TDR data, APSIM estimated a plant available water capacity (PAWC) of $40.75 \mathrm{~mm}$ for the 'low' zone down to $55 \mathrm{~cm}$ depth, according to the DUl and LL values used for the soil characterisation. Overestimation of soil moisture was observed, especially for summer months, when observed draining events were more pronounced than estimated. This could be due to the variability of irrigation at the area. Hence, there was a mismatch between the amount of water measured by the tipping bucket method and actual water applied over the probes.

For the 'medium' zone, Figure 5 shows a more robust estimation of volumetric soil water content based on the TDT tapes than were estimated from the TDR probes. Values of RMSD of $4 \%, 5 \%$ and $7 \%$ were obtained for the estimations based on the TDR probes for $170 \mathrm{~mm}$, $300 \mathrm{~mm}$ and $400 \mathrm{~mm}$ depth, respectively. Estimations based on observed data from the TDT tapes had RMSD 


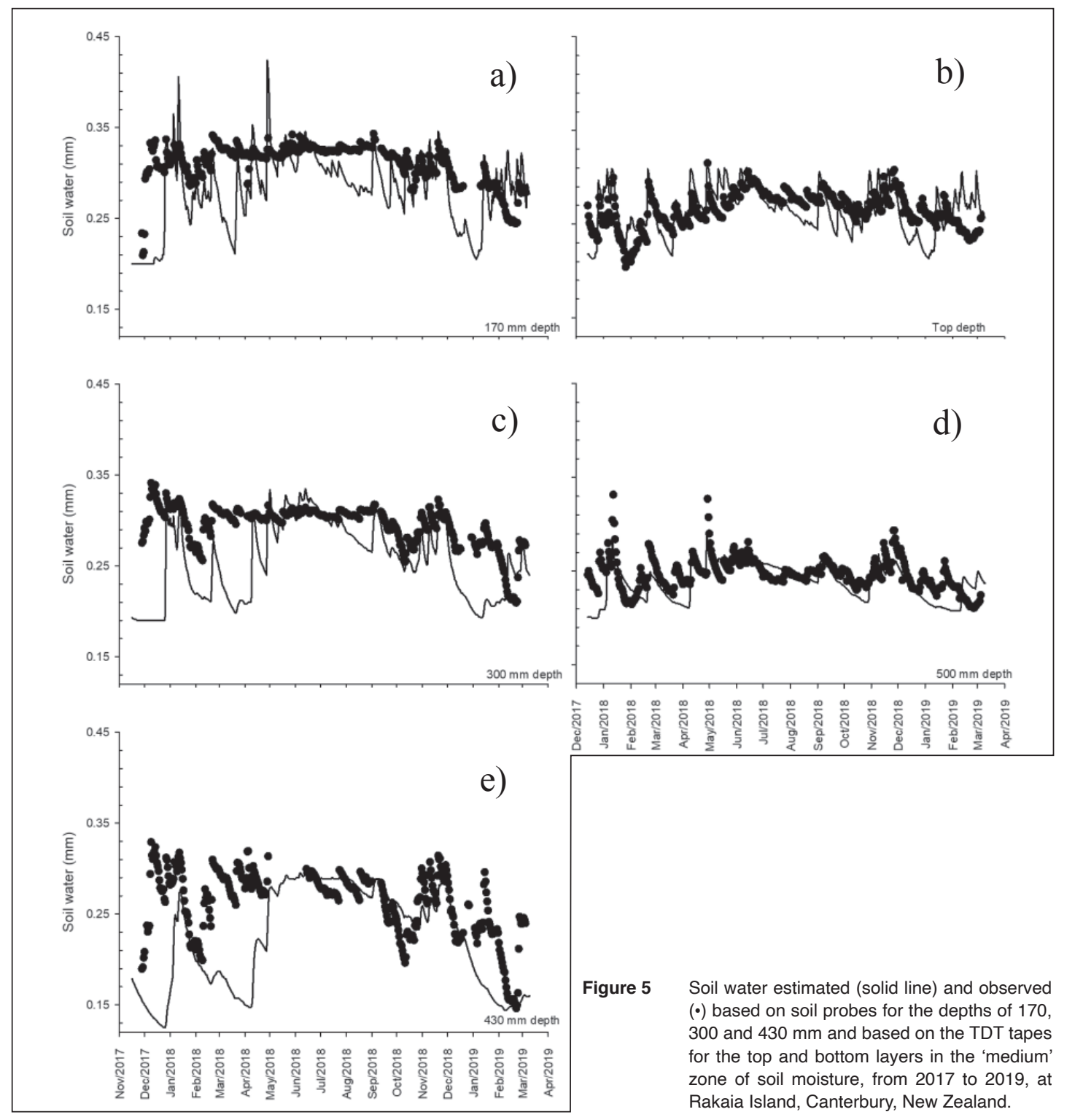

values of $2 \%$ for both top and bottom layers. Based on the RMSD values and visual observation of Figure 5 , the estimations of volumetric soil water content based on the TDT tapes were chosen to provide annual estimations of dry matter production for the 'medium' zone. In this case, the estimated PWHC down to a depth of $65 \mathrm{~cm}$ was $99.5 \mathrm{~mm}$, based on DUL and LL values was used.

Readings from the TDR probes were used to estimate the soil PAWC for the 'low' zone whereas the TDT tapes were used to estimate PAWC for the 'medium' zone. This was because the information provided by the TDR probes was more appropriate to estimate AWC for thinner layers of soil. This was crucial to improve the estimates for stony soils, because roots do not have a uniform distribution in such soils (Sim et al., 2017).

\section{Dry matter yield estimation}

Monthly growth rates estimated for the 'low' and 'medium' zones and observed from weekly C-DAX and rising plate meter measurements are presented in Figure 6. The APSIM-modelled growth rates were in alignment with the observed monthly growth rates for most of the period where observed soil moisture data was recorded. Overestimation of growth rates was seen for the period between October 2018 and January 2019. However, the estimated growth rate for this period was in agreement with the previous season observed data, obtained from 

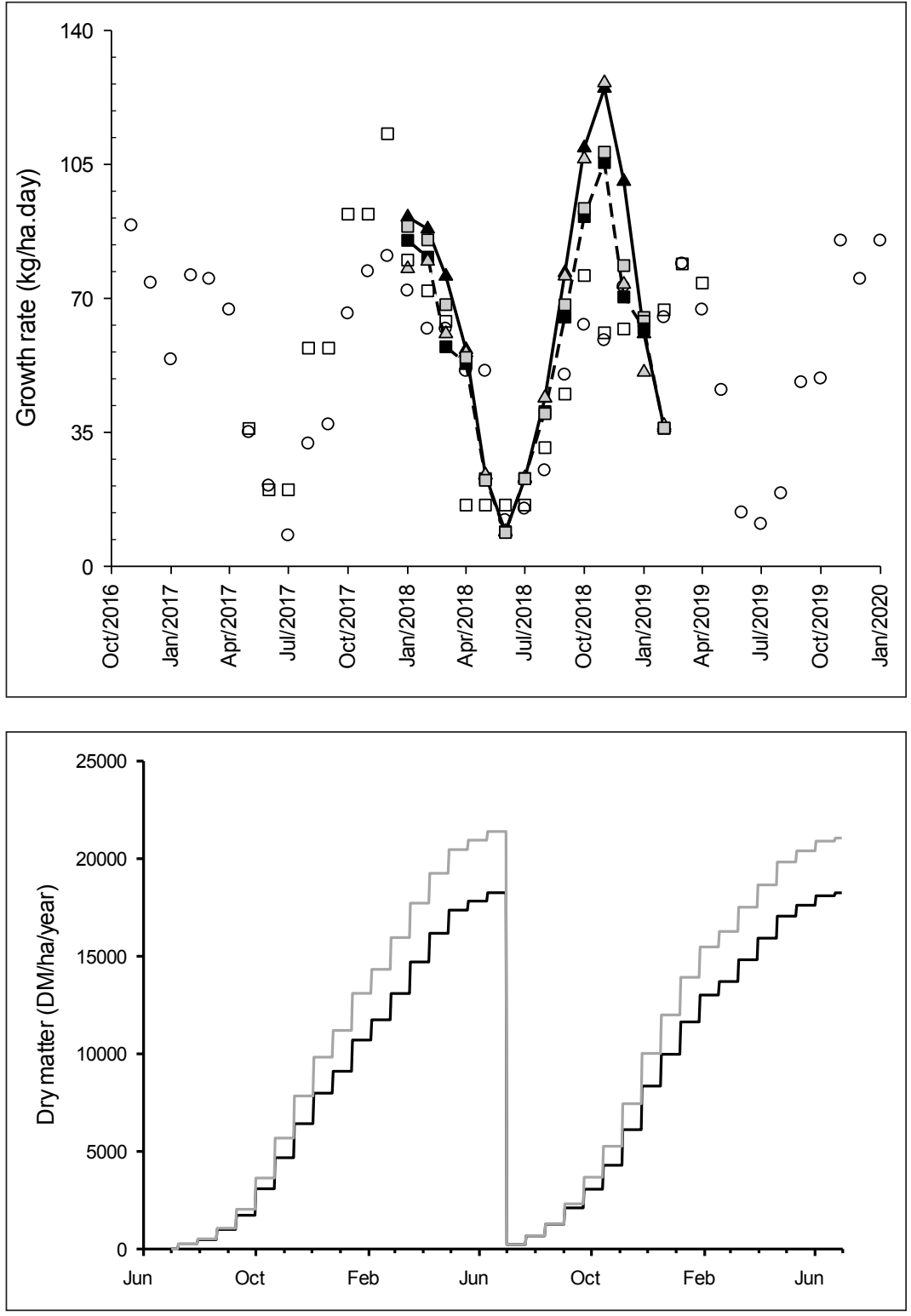

Figure 6

Monthly growth rates for Rakaia Island Dairies estimated using APSIM (closed symbols) for the 'low' ( $\boldsymbol{\square}$ ) and 'medium' ( $\boldsymbol{\Delta}$ ) zones and observed growth rates (open symbols) obtained from farm walks (०) and from Zydenbos et al., (2019) (口)from October 2016 to January 2020, in Canterbury, New Zealand.

\section{Figure 7}

Simulated annual dry matter production for 'low' (black) and 'medium' (grey) soil moisture zones under a uniform irrigation schedule. Yields simulated for two seasons, from July 2017 until June 2018 and July 2018 until June 2019, for a hypothetical farm in Canterbury, New Zealand. the grass grub study (Zydenbos et al., 2019). During the period when pasture is growing fastest and grazing rotation lengths are shortest, underestimation of the pasture growth is more likely, especially when using farm walk data (Dalley and Geddes 2012). Given that these are not direct measurements of the exact same areas, the overall conclusion was that the estimation of growth rates was sensible and in agreement to that measured at Rakaia Island on previous occasions.

\section{System modelling}

Modelled pasture production for 'low' and 'medium' soil moisture zones under a uniform irrigation is presented in
Figure 7. The estimated average annual production for the 'low' zone of soil moisture was $18.3 \mathrm{t} \mathrm{DM} / \mathrm{h}$, whereas the 'medium' zone had an average estimation of $21.2 \mathrm{t}$ $\mathrm{DM} / \mathrm{ha}$. The difference of approximately $2900 \mathrm{~kg} \mathrm{DM} /$ ha was used to model hypothetical production systems in FARMAX, based on low and medium soil types.

The 'low' zone was measured as $20 \%$ of VRI area on the study farm, and FARMAX modelling analysis examined the potential farm systems impact of increasing pasture production in this 'low' zone to that estimated for the 'medium' zone. This equated to an additional $580 \mathrm{~kg} \mathrm{DM} / \mathrm{ha} /$ year available on the $100 \%$ medium farm system. 
The extra pasture grown in the $100 \%$ 'medium' zone scenario could be utilised in a variety of ways, including increasing herd size, feeding more per head, selling extra pasture as silage or buying less silage and using less nitrogen. For this approach, increasing herd size was used. This resulted in a simpler model overall, with less interpretation required for farmer decision/management changes and a 'typical irrigated Canterbury System 4 dairy farm' was maintained.

An additional $580 \mathrm{~kg} \mathrm{DM} / \mathrm{ha}$ across the whole farm when modelled in FARMAX, resulted in an increase of $51 \mathrm{~kg} / \mathrm{ha}$ milksolids and stocking rate by $0.2 \mathrm{cow} /$ ha. Using a milk price of $\$ 7.10 / \mathrm{kg}$ MS (Fonterra 2019-2020) resulted in a profit increase of $\$ 298 / \mathrm{ha} /$ year or $\$ 75,000$ over a 255 ha farm (Table 3). On a regional scale, increasing the productivity of the $18 \%$ of irrigated Canterbury dairy land $(52,900 \mathrm{ha})$ that would be considered in the 'low' zone to match the productivity of the 'medium' zone soils, would equate to an additional $\$ 14 \mathrm{M}$ profit to dairy farmers on these soils.

\section{Discussion}

An innovation systems approach to prioritise opportunities to increase efficiency of resource use on high performing dairy farms has demonstrated on-going potential for continuous improvement (Zydenbos et al., 2019). Further optimisation of irrigation systems to better match water application with soil characteristics could deliver more pasture growth and milk production or the same production with less supplementary feed. Understanding the potential 'size of the prize' within the farm can assist in strategic planning for investment in irrigation hardware, software, sensors and technical training for farm staff. Farm owner Dave Turner noted the value in the research, saying 'we can control when and how we apply water, but not change our soils'. The theoretical value created by increasing productivity of 'low' zone soils, representing $20 \%$ of a 255 ha modelled farm, was $\$ 75,000$ per annum; a significant contribution to the investment required to improve the strategic planning of irrigation.

A unique aspect of the innovation systems approach at RID was the diversity in data collection and the capacity to evaluate the opportunities to optimise irrigation with actual data and its inherent, often poorly understood variability. The 'low' moisture zone at Rakaia Island Dairies was considered a stony soil, with $53 \%$ stones from 0 to $22 \mathrm{~cm}$ depth, $65 \%$ from 22 to 34 $\mathrm{cm}$ depth and $67 \%$ from 34 to $99 \mathrm{~cm}$ depth. Typical stony soils of the Canterbury plains are characterised by thin top soil layers that are often on top of layers that have more than $50 \%$ of the soil volume as stones (Di and Cameron 2002). This can create a similar effect to compaction, where roots can agglutinate in macropores
(Dardanelli et al., 2004). This could be the reason for the stronger estimation of soil moisture in the 'low' zone provided by the fit of the observed data from the TDR (Figure 4). For the 'medium' zone, an improved fit was observed between the estimated and observed values obtained with the TDT tapes. This could be due to the fact that the TDR probes were damaged and had to be re-installed. Furthermore, the lack of stones, or any other impediment for root development, and the higher moisture of this zone, allowed a more homogenous distribution of roots through the soil profile (Rich and Watt 2013). For this reason, a more detailed split of soil layer may not be needed, allowing for a satisfactory fit from the TDT tape data.

As the method for soil moisture simulation was established, AgPasture was used to estimate pasture production based on the observed soil moisture. This provided monthly growth rates that were compared to those observed obtained in the same area (Zydenbos et al., 2019) (Figure 6). In general, there was strong alignment between farm-collected data and the estimated APSIM values, even though there was an overestimation for the summer period between 2018 and 2019. For example, farm walk data showed similar growth rates particularly in the slower growing months, while Zydenbos et al. (2019) recorded annual pasture production of up to $21 \mathrm{t} \mathrm{DM} / \mathrm{ha} /$ year in separate trials on the same area

To directly evaluate production differences between the two moisture zones, a second simulation of dry matter production was done based on a similar irrigation amount for the two zones (Figure 7). The difference of $2.9 \mathrm{t} \mathrm{DM} /$ ha between the two zones was then used to model hypothetical farming systems in FARMAX. This was similar to the $2.7 \mathrm{t} / \mathrm{h}$ a difference obtained by Brown et al. (2020), who compared ryegrass biomass production of a seed crop grown under high, medium and low zones of soil moisture. This supported the assumption that the estimated differences were robust enough to progress with the evaluation of yield gap analysis on FARMAX.

Irrigation is a key element of the high performance from the Dairy 1 unit, but despite the farm goal of maximising pasture production along with investment in irrigation infrastructure and management, there was still a penalty in annual pasture production from 'low' compared to the 'medium' zone. This finding posed an interesting question: what is the productive potential if irrigation application was truly optimised? As noted above, the value created from achieving this potential was significant $(\$ 75,000$ per annum on farm) and the 'size of the prize' at a regional level could be substantial (\$14 M per annum). Further, the model did not investigate the environmental benefits or opportunities to reduce use of supplements or nitrogen fertiliser, and 
these factors may add even more significant value.

Managing variability in irrigation remains challenging, with a range of factors impacting on efficiency. This variability was evident in the actual irrigation application data as a difference in irrigation application over the year between the two zones, which were in different paddocks, yet irrigated by the same centre pivot machine. The variability in irrigation application along the length of the pivot recorded on this farm has been reported previously (Thomas et al., 2006). Reasons for this variation include faulty, damaged or blocked nozzles, variable pressure in the line due to hardware limitations, including function of and demand for water pumps supplying more than one irrigator. Thomas et al. (2006) measured the variability along the same irrigator on different occasions and noted that it changed over time.

Taking an innovation systems approach provided an opportunity to use a blend of collected and modelled data in assessing systems opportunities. If pasture production can be increased from optimised irrigation application, this has positive implications for the farming system. With an estimated 52,900 ha of irrigated dairy pastures may be in the 'low' zone, the 'size of the prize' for the region and industry are substantial and not only an opportunity to provide additional milksolids production but also to contribute to reducing the environmental footprint of these farms.

The next step in this research is to co-design, with industry partners, an investigation of the cost:benefit of effectively using the VRI pivot to tailor the irrigation to each zone by testing a number of different application scenarios.

\section{Conclusions}

The APSIM modelling carried out in this study has shown that, under a constant uniform irrigation application, soils characterised by EM mapping as low PWHC produce less pasture per annum than 'medium' zone soils. The value of this lost production was significant at a farm $(\$ 75,000)$ and regional $(\$ 14 \mathrm{M})$ level.

\section{ACKNOWLEDGEMENTS}

The work was undertaken as part of the "Future Farm Systems Rakaia Island project" with Ravensdown. Inkind support was provided by Rakaia Island Dairies (Dave and Margaret Turner, Doug and Helen Turner and Rory Mackay), with special mention of Jared Porter, farm manager of Dairy1 at the time. Willis Richie, Ray Moss, Tom Orchiston, Mostafa Sharifi, Russel McAuliffe and Trevor Knight, AgResearch, organised collection and collation of data. Peter Pletnyakov, AgResearch, contributed to collation and analysis of some of the datasets. Thanks to Rogerio Cichota, Plant and Food Research, for discussions about the APSIM modelling approach.

\section{REFERENCES}

APSIM. 2020. Documentation: SoilWat https://www. apsim.info/documentation/model-documentation/ soil-modules-documentation/soilwat/.

Brown HE, Jamieson PD, Hedley C, Maley S, George MJ, Michel AJ, Gillespie RN. 2020. Using infrared thermometry to improve irrigation scheduling on variable soils. Agricultural and Forest Meteorology https://doi.org/10.1016/j.agrformet.2020.108033.

Bryant J, Ogle G, Marshall PR, Glassey CB, Lancaster JAS, Garcia SC, Holmes CW. 2010. Description and evaluation of the Farmax Dairy Pro decision support model. New Zealand Journal of Agricultural Research 53: 13-28. https://doi. org/10.1080/00288231003606054

C-Dax Ltd. 2019. Pastoral 21 results for C-Dax Pasture Meter. Accessed: 30/8/2019 from http://www.c-dax. co.nz/index.php?page=shop/articleandarticle_id $=80$.

Clark CEF, Romera AJ, Macdonald KA, Clark DA. 2010. Inter-paddock annual dry matter yield variability for dairy farms in the Waikato region of New Zealand. New Zealand Journal of Agricultural Research 53(2): 187-191. https://doi.org/10.1080/00 288233.2010.482964

DairyNZ. 2015/16. DairyBase benchmarks https:// www.dairynz.co.nz/business/dairybase/latestdairybase-benchmarks.

Dalley DE, Geddes T. 2012. Pasture growth and quality on Southland and Otago dairy farms. Proceedings of the New Zealand Grassland Association 74: 237242. https://doi.org/10.33584/jnzg.2012.74.2870

Dardanelli JL, Ritchie JT, Calmon M, Andriani JM, Collino DJ. 2004. An empirical model for root water uptake. Field Crops Research 87 (1): 59-71. http:// dx.doi.org/10.1016/j.fcr.2003.09.008

Di HJ, Kemp RA. 1989. Variation in soil physical properties between and within morphologically defined series taxonomic units. Soil Research 27: 259-273. https://doi.org/10.1071/SR9890259

Di HJ, Cameron KC. 2002. Nitrate leaching and pasture production from different nitrogen sources on a shallow stoney soil under flood-irrigated dairy pasture. Soil Research 40: 317-334. https://doi. org/10.1071/SR9890259

Fonterra. 2019-2020. Fonterra milk schedule https:// www.fonterra.com/nz/en/investors/farmgate-milkprices.html.

Hall A. 2007. The origins and implications of using innovation systems perspectives in the design and implementation of agricultural research projects: Some personal observations. Presented at: United Nations University, Maastricht Economic and Social 
Research and Training Centre on Innovation and Technology. UNU-MERIT Working Paper Series. https://www.researchgate.net/publication/4790304.

Hedley CB, Roudier P, Yule IJ, Ekanayake J, Bradbury S. 2013. Soil water status and water table depth modelling using electromagnetic surveys for precision irrifation scheduling. Geoderma 199: 2229. https://doi.org/10.1016/j.geoderma.2012.07.018

King WM, Rennie GM, Dalley DE, Dynes RA, Upsdell MP. 2010. Pasture mass estimation by the C-DAX pasture meter: regional calibrations for New Zealand. Presented at: Proceedings of the 4th Australasian Dairy Science Symposium. Pp. 233-238. http://www. sciquest.org.nz/node/149545

Li FY, Snow VO, Holzworth DP. 2011. Modelling the seasonal and geographical pattern of pasture production in New Zealand. New Zealand Journal of Agricultural Research 54 (4): 331-352. https://doi.or $\mathrm{g} / 10.1080 / 00288233.2011 .613403$

LIC/DairyNZ. 2009. New Zealand Dairy Statistics Retrieved 23/07/2020, from https://d1r5hvvxe7dolz. cloudfront.net/media/documents/DAIRYSTATISTICS-08-09.pdf.

LIC/DairyNZ. 2019. New Zealand Dairy Statistics Retrieved 23/07/2020, from https://d1r5hvvxe7dolz. cloudfront.net/media/documents/2018-19_New_ Zealand_Dairy_Statistics.pdf.

Manaaki Whenua Landcare Research. 2019. S-map New Zealand's national digital soil map. 10.7931/ L1WC7 https://datastore.landcareresearch.co.nz/ dataset/s-map.

Ministry for the Environment. 2017a. Irrigated land area, 2017 Retrieved 7 July 2021 from: https://data. mfe.govt.nz/layer/90838-irrigated-land-area-2017/.

Ministry for the Environment. 2017b. Nitrate-nitrogen leaching from dairy livestock 2017 Retrieved
7 July 2021 from: https://data.mfe.govt.nz/ layer/99898-nitrate-nitrogen-leaching-from-dairylivestock-2017/.

NIWA. 2020. National climate database https://cliflo. niwa.co.nz/.

Rich SM, Watt M. 2013. Soil conditions and cereal root system architecture: review and considerations for linking Darwin and Weaver. Journal of Experimental Botany 64 (5): 1193-1208. https://doi.org/10.1093/ jxb/ert043

Sim RE, Brown HE, Teixeira EI, Moot DJ. 2017. Soil water extraction patterns of lucerne grown on stony soils. Plant Soil 414: 95-112. https://link.springer. com/article/10.1007/s11104-016-3112-x

Tait A, Turner R. 2005. Generating multiyear gridded daily rainfall over New Zealand. Journal of Applied Meteorology 44: 1315-1323. https://doi.org/10.1175/ JAM2279.1

Thomas SM, Bloomer D, Martin RJ, Horrocks A. 2006. Spray irrigation on dairy pastures - efficient or not? Proceedings of the New Zealand Grassland Association 68: 177-181. https://doi.org/10.33584/ jnzg.2006.68.2656

Van Ittersum MK, Cassman KG, Grassini P, Wolf J, Tittonell P, Hochman Z. 2013. Yield gap analysis with local to global relevance - a review. Field Crops Research 143: 4-17. https://doi.org/10.1016/j. fcr.2012.09.009

Zydenbos SM, Taylor AL, Yang W, O'Callaghan M, Hardwick S, Townsend RJ, Meenken ED, Manning MJ, Roberts AHC, Dynes RA. 2019. An innovation systems approach to understanding the impacts of grass grub damage in irrigated Canterbury dairy pastures. Journal of New Zealand Grasslands 81: 163170. http://dx.doi.org/10.33584/jnzg.2019.81.412 